\title{
Carreiras Sem Fronteiras em uma Instituição Financeira Brasileira de Grande Porte
}

\author{
Thais Carazato Pisapia \\ Escola de Administração de Empresas de São Paulo da Fundação Getúlio Vargas, \\ São Paulo, SP, Brasil \\ Thomaz Wood Jr. \\ Escola de Administração de Empresas, da Fundação Getúlio Vargas, São Paulo, SP, Brazil \\ Pedro F. Bendassolli ${ }^{1}$ \\ Departamento de Psicologia da Universidade Federal do Rio Grande do Norte, \\ Natal, RN, Brasil
}

\section{Resumo}

Nos últimos anos, mudanças nas empresas e na organização do trabalho levaram ao surgimento de novos modelos de carreiras. Entre tais modelos, ganhou proeminência o modelo de carreiras sem fronteiras, que tem como premissa uma alta mobilidade profissional. No Brasil, entretanto, ainda há poucos estudos empíricos sobre o fenômeno. Esta pesquisa procurou endereçar esta lacuna. O objetivo deste trabalho foi identificar as atitudes dos indivíduos frente à carreira em uma instituição financeira brasileira de grande porte. Metodologicamente, o estudo utilizou um desenho misto. A parte quantitativa consistiu na aplicação da Boundaryless Career Attitudes Scale, previamente validada para utilização em língua portuguesa. A escala foi aplicada a 126 profissionais de sete áreas da referida organização. A parte qualitativa envolveu a realização de 11 entrevistas em profundidade com profissionais identificados da base de respondentes da parte quantitativa. Os resultados indicam forte presença de atitudes de carreira sem fronteiras dentro da organização, embora haja diferenças entre áreas e entre indivíduos, fruto de seu tempo de trabalho na organização. $\mathrm{O}$ artigo procura explicar as razões para estas diferenças e discute o aparente paradoxo entre uma elevada atitude para carreira sem fronteiras e a constatação de um forte desejo de permanência e vínculo com a organização. $O$ trabalho contribui para a construção do conhecimento no campo de estudos de carreiras no Brasil, à medida que utiliza uma escala validada de atitudes e revela a realidade de uma grande organização local. $\mathrm{O}$ artigo também indica possibilidades para futuras pesquisas no campo.

Palavras-chave: Carreiras profissionais no Brasil, novos modelos de carreira, carreira sem fronteiras, mobilidade profissional, instituição financeira.

\section{Boundaryless Careers in a Large Brazilian Financial Institution}

\begin{abstract}
In recent years, changes in business and in work organization led to the emergence of new career models. Among these models, the boundaryless careers model has gained prominence. This model is premised on a high professional mobility. In Brazil, however, there are still few empirical studies on the phenomenon. This research sought to address this gap. The objective of this study was to identify the
\end{abstract}

Endereço para correspondência: Rua Vicente Mesquita, 885, Apto. 501, Natal, RN, Brasil 59063-650. Fone: (84) 3025-3040. E-mail: thais_pisapia@yahoo.com.br, thomaz.wood@fgv.bre pbendassolli@gmail.com 
attitudes of individuals regarding careers in a large Brazilian financial institution. Methodologically, the study used a mixed-method design. The quantitative part consisted on the application of the Boundaryless Career Attitudes Scale, previously validated for use in Portuguese language. The scale was applied to 126 professionals in seven areas of the organization. The qualitative part involved the completion 11 interviews with professionals who had previously answered the quantitative part. The results indicate a strong presence of the boundaryless career attitudes within the organization, although there were differences among areas and among individuals, this last being the result of their working time in the organization. The article seeks to explain the reasons for these differences and discusses the apparent paradox between a high attitude toward boundaryless careers and a strong desire to keep the professional relationship with the organization. The work contributes to the building of knowledge in the field of career studies in Brazil, as it uses a validated scale of attitudes and reveals the reality of a large local organization. The article also indicates possibilities for future research in the field.

Keywords: Careers in Brazil, new models of career, boundaryless career, professional mobility, financial institution.

\section{Carreras Sin Fronteras en una Gran Institución Financiera Brasileña}

\section{Resumen}

En los últimos años, los cambios en los negocios y en la organización del trabajo llevado a la aparición de nuevos modelos de carrera. Entre estos modelos, el modelo carreras sin fronteras ha ganado prominencia. Esto modelo se basa en una alta movilidad. En Brasil, sin embargo, existen pocos estudios empíricos sobre el fenómeno. Esta investigación busca llenar este vacío. El objetivo de este estudio fue identificar las actitudes de los individuos a la carrera dentro de una grande institución financiera de Brasil. Metodológicamente, el diseño del estudio se utilizó una mezcla cuantitativa y cualitativa. La parte cuantitativa fue la aplicación de la Boundaryless Career Attitudes Scale, previamente validado para su uso en portugués. La escala se administró a 126 profesionales en siete áreas de la organización. La parte cualitativa implicó la realización de 11 entrevistas con profesionales de la base de de la parte cuantitativa. Los resultados indican una fuerte presencia de las actitudes de carrera sin fronteras dentro de la organización, aunque hay diferencias entre áreas y entre los individuos, el resultado de su tiempo trabajando en la organización. El artículo trata de explicar las razones de estas diferencias y se analiza la aparente paradoja entre una actitud hacia la carrera sin fronteras y un fuerte deseo de permanecer en la organización. El trabajo contribuye a la construcción del conocimiento en el campo de los estudios de la carrera en Brasil, ya que utiliza una escala validada de las actitudes y revela la realidad de una organización local.

Palabras clave: Carreras en Brasil, nuevos modelos de la carrera, carrera sin fronteras, movilidad profesional, institución financiera.

A palavra carreira, com significado de oficio, profissão com etapas ascendentes, nasceu com o surgimento da sociedade industrial, ganhando, com o tempo, um significado implícito de percurso profissional ou de vida (Chanlat, 1995; Dubar \& Tripier, 2005; Inkson, 2007). Segundo London e Bray (1984), carreiras caracterizam-se por uma série de posições ocupadas e de trabalhos realizados durante a vida profissional de um indivíduo. Referem-se às experiências de uma pessoa com o trabalho, envolvendo tanto aspectos objetivos como subjetivos (Arthur, Hall, \& Lawrence, 1989).

Assim, de um lado, existem os motivos e aspirações do indivíduo, e, de outro, os condicionantes ou imposições da organização e da so- 
ciedade. Para o indivíduo, a carreira acompanha a evolução da experiência profissional. Para a organização, envolve a definição de diretrizes, processos e decisões relacionadas a funções, cargos, remuneração e movimentação de profissionais. $\mathrm{Na}$ literatura, essa dupla natureza da carreira é alimentada tanto nas tradições da psicologia vocacional ou de orientação profissional, como nas tradições gerenciais (Gunz \& Peiperl, 2007).

$\mathrm{Na}$ entrada para o século XXI, o campo de estudo sobre carreira acumulou várias linhas de debates e controvérsias, parte das quais associada a essa dupla natureza da carreira, ao mesmo tempo social e pessoal. Por exemplo, Peiperl e Arthur (2000) destacam quatro focos de discussão nesse domínio: (a) entre agência e estrutura, quando se debate o quanto as carreiras são produto da ação individual ou dos condicionantes institucionais; (b) entre estabilidade e mudança, referindo-se ao quanto o mundo das carreiras é assumido como relativamente invariável ao longo do tempo, ou, pelo contrário, como sujeito a contínas transformações; (c) entre universalismo e particularismo, seja com respeito a pressupostos sobre a própria natureza humana e aos modos de conhecê-la, como também com respeito aos conceitos e termos utilizados para descrever as carreiras nos mais variados contextos e culturas; e (d) entre conhecimento institucional e conhecimento individual, algo similar à discussão sobre qualificações (mais coletivas e institucionalizadas) e competências (mais flexíveis e pertencentes ao o próprio indivíduo, permitindo a este transferi-las de um cargo/organização para outro; e.g., Inkson \& Parker, 2005).

Embora essas quatro linhas de debate tenham sido identificadas há mais de uma déca$\mathrm{da}$, elas ainda parecem fazer sentido quando se pensa no tema das carreiras na atualidade. Por exemplo, é comum se contrastar a época atual (especialmente a que se inicia na virada dos anos de 1990, no Brasil), marcada por novos arranjos e contratos de trabalho, com uma época pregressa, em que os empregos eram mais estáveis e as perspectivas de crescimento e desenvolvimento de carreira, mais lineares (e.g., Dutra, 2009; Kilimnik, 2011). De fato, o último quartil do século XX foi marcado por privatizações, fusões, aquisições, reestruturações, terceirizações e processos de redução de quadros. Tais mudanças trouxeram novos desafios e oportunidades para os profissionais. Porém, ao mesmo tempo em que facilitaram a mobilidade dentro da empresa e entre empresas, reduziram a estabilidade no emprego e provocaram mudanças no vínculo entre indivíduo e organização (Grzeda, 1999; Rousseau, 1995).

Nesse cenário, emergiu uma nova concepção de carreira, fundamentada em uma maior valorização da responsabilidade individual do profissional (Fontenelle, 2007; Stickland, 1996). O conceito de emprego, baseado na estabilidade e em posições de trabalho claras e bem definidas, deu progressivamente espaço à ênfase na contínua adaptação do indivíduo dentro de um ambiente em rápida transformação (Beck, 2000). Em resposta a essas mudanças nas formas de institucionalização do trabalho, a própria literatura sobre carreira foi se transformando. Assim, de um foco nas carreiras organizacionais (Hall, 1976; Van Maanen, 1977), se passa a debater novos modelos e arranjos de carreira, denominados por alguns autores como modelos emergentes ou não tradicionais de carreira (e.g., Bendassolli, 2009; Sullivan, 1999).

Os novos modelos buscam ajustar a teorização sobre carreiras às transformações demográficas, econômicas, laborais, sociais, organizacionais e tecnológica que afetaram a concepção clássica de carreira. Tal concepção estava fundamentada em rotinas, processos, sistemas regulatórios e estruturas institucionais mais estáveis que as existentes hoje (Inkson, 2007).

Entre os novos modelos, podemos destacar a carreira proteana (Hall, 1976, 2002, 2004); a carreira sem fronteiras (Arthur; 1994; Arthur, Inkson, \& Pringle, 1999; Arthur \& Rousseau, 1996); a carreira portifólio (Baruch, 2004, 2006; Borgen, Amundson, \& Reuter, 2004; Inkson \& Baruch, 2009; Templer \& Cawsey, 1999); e a carreira narrativa (e.g., McMahon \& Patton, 2006; Savickas, 2009).

Entre esses modelos, um em particular será foco deste artigo. Trata-se do modelo da carreira sem fronteiras, definida por Arthur e Rousseau (1996) como ". . . o oposto da "carreira orga- 
nizacional' - carreiras concebidas para se desenvolver dentro de um único contexto de emprego" (p. 5). A característica mais conhecida desse modelo é a mobilidade, que se refere à passagem do profissional por várias áreas dentro de uma organização e por várias organizações. No entanto, o modelo compreende outras características relevantes, além da mobilidade. Arthur e Rousseu citam a possibilidade de realização do trabalho de forma autônoma; o uso, pelos indivíduos, de redes externas de relacionamento; a transição de funções técnicas para funções gerenciais; a possibilidade de reduzir o tempo dedicado ao trabalho, em favor de mais tempo passado com a família ou em atividades paralelas; e a percepção do próprio indivíduo, que pode vislumbrar trajetórias profissionais sem obstáculos estruturais.

Da maneira como definido por Arthur e Rousseau (1996), a carreira sem fronteiras contrasta com o conceito de carreira organizacional. Enquanto esta última se desenvolve por meio do avanço profissional de um indivíduo dentro de uma hierarquia formal na organização, a carreira sem fronteiras se desdobra em uma sequência temporal de experiências de trabalho que não se limita às fronteiras de uma única organização, ocupação ou mesmo país. Assim, a verticalidade do modelo tradicional, no qual o indivíduo dedicava frequentemente sua vida a uma única empresa é substituída pela transversalidade da carreira sem fronteiras (Bendassolli, 2009).

Um aspecto essencial do modelo de carreiras sem fronteiras refere-se às competências a ele associadas. Toda carreira pode ser entendida como a trajetória das experiências de trabalho do individuo, nas quais este adquire vários tipos de conhecimento. A sequência de criação de conhecimento define ou molda a carreira (Mendenhall, Kuhlmann, \& Stahl, 2001). De acordo com DeFillippi e Arthur (1994), o indivíduo precisa desenvolver três conjuntos de competências essenciais para estruturar sua carreira (esses autores referem-se ao modelo de carreira sem fronteiras, mas as competências estão igualmente presentes na discussão de outros modelos de carreira): know-why (saber por quê), know-how (saber como) e know-whom (saber com quem).
As competências know-why, conforme descrevem DeFillippi e Arthur (1994), referem-se às motivações para a realização da atividade: o significado pessoal e a identificação com o trabalho. As competências know-how compreendem as habilidades e os conhecimentos necessários para o bom desempenho do trabalho, sendo especialmente relevantes as competências que podem ser "transportadas" de um contexto para outro. Por fim, as competências know-whom referem-se às redes de relacionamento desenvolvidas durante a vida profissional. Centra-se no capital social, do qual derivam informação, influência e solidariedade entre pessoas que mantêm contato ou convivem entre si.

O modelo de carreira sem fronteiras ensejou, desde sua proposição no final dos anos de 1990, diversos estudos teóricos e empíricos (para uma síntese, ver Tams \& Arthur, 2010). Na literatura internacional, por exemplo, há investigações sobre a relação entre gênero e mobilidade (e.g., Forret, Sullivan, \& Mainiero, 2010); entre determinados setores (como o de tecnologia) e a viabilidade do modelo de carreiras sem fronteiras (e.g., Inkson \& Parker, 2005); sobre competências e carreira (e.g., Colakoglu, 2011; Eby, Butts, \& Lockwood, 2003), apontando que maiores níveis de competências dos três tipos apresentados anteriormente (know-why, kwno-how e know-whom) estão associados a maiores níveis de percepção de sucesso. Mas também podem ser encontrados estudos que questionam a amplitude do conceito de carreiras sem fronteiras, ou mesmo sua viabilidade prática. Currie, Tempest e Starkey (2006), por exemplo, argumentam que esse modelo pode ser atrativo para trabalhadores mais qualificados e mais jovens, mas não para trabalhadores mais velhos e com qualificações mais genéricas. Resultado similar é apresentado por Pringle e Mallon (2003), cuja investigação aponta para potenciais limites do modelo de carreira sem fronteiras quando se considera o pertencimento a determinados grupos étnicos e culturas coletivas.

No Brasil, os estudos sobre novos modelos de carreira se intensificam a partir do início do anos de 2000 (Balassiano, 2006; Dutra, 2009). Podem ser citados estudos sobre os novos mo- 
delos de carreira (e.g, Bendassolli \& Wood, 2010; Dutra, 2009; Kilimnik, 2011; Kilimnik, Sant'Anna, \& Castilho, 2007; Lacombe, 2005; Scalabrin, 2008), mas também uma diversidade de outros tópicos, como a relação entre comprometimento organizacional, identidade com o trabalho e sucesso na carreira (e.g, Bastos \& Andrade, 2002); a autogestão da carreira (Fontenelle, 2007); e estudos relacionados especificamente à temática deste artigo, a saber: a presença do tema da carreira sem fronteiras no setor financeiro.

Por exemplo, Veloso e Dutra (2011) estudaram a situação dos profissionais do antigo Banespa, banco estatal paulista privatizado em 2000. Mostram que, independentemente da decisão desses profissionais de permanecer ou sair da organização (demissão voluntária), o modo como gerenciam sua carreira é determinante na maneira como manejam sua transição profissional. Com isso, os autores sugerem que as carreiras sem fronteiras podem não estar, necessariamente, relacionadas à mobilidade física. Elas podem ser desenvolvidas mesmo no contexto de empregos estáveis, desde que as atitudes profissionais sejam condizentes com esse tipo de carreira (mobilidade psicológica). Já na pesquisa de Oltramari e Lorenzato (2012) são destacadas as tensões e dilemas envolvidos na construção de uma carreira sem fronteira por gerentes bancários. Notadamente, a tensão entre a pressão da organização para que seus profissionais desenvolvam atitudes de mobilidade física e, sobretudo, psicológica, e a dificuldade em conciliar essas exigências com a vida familiar.

Tendo em vista a necessidade de ampliar a literatura nacional acerca das carreiras contemporâneas e a relevância de explorar sua manifestação em diferentes segmentos, apresentamos o presente estudo, que tem por objetivo investigar a presença de atitudes relacionadas à carreira sem fronteiras em uma instituição bancária de grande porte. A escolha por esse segmento se deve, entre outros motivos, pelo fato de ser esse um setor em que se podem identificar, ao mesmo tempo, uma confluência de múltiplas "carreiras" (desde tecnologia e gestão da informação, até atividades mais operacionais), intensa concen- tração e verticalização organizacional (o setor hoje, no Brasil, possui uma característica de concentração em poucos e grandes grupos), e uma ideologia gerencial consoante às características das carreiras sem fronteiras, tais como mobilidade física, expatriações e políticas de gestão enfatizando a autorresponsabilidade pelo crescimento profissional e pelo desempenho (Oltramari \& Lorenzato, 2012).

Adicionalmente, alguns estudos têm questionado se as atitudes de carreira sem fronteiras são constructos amplamente compartilhados, independentemente da cultura e do contexto. Por exemplo, Gerber, Wittekind, Grote, Conway e Guest (2009) mostram que, apesar do discurso, a generalização das orientações de carreira não se sustentam transculturalmente. Inclusive, esses autores citam pesquisas nas quais se identificam preferências por carreiras "tradicionais", sinônimos de estabilidade e segurança. Dessa forma, considerando o contexto de uma grande organização bancária privada brasileira, em que há forte incentivo para o desenvolvimento profissional e programas vantajosos de remuneração, teriam os profissionais preferências por carreiras sem fronteiras? Em caso afirmativo, como isso poderia ser conciliado com o emprego quase-estável desses profissionais, considerando, como será descrito mais adiante, seu tempo de atuação no banco? Haveria alguma relação entre a atitude de carreira sem fronteira e variáveis como área de atuação, cargo, formação profissional, número de mudanças dentro da própria organização e ao longo da carreira?

Para responder a estas questões, este estudo adota o referencial do modelo de carreira sem fronteiras. Emprega-se uma metodologia mista, baseada na exploração de relações quantitativas do fenômeno e no aprofundamento qualitativo, realizado por meio de entrevistas. Em seguida, são apresentados os métodos adotados.

\section{Método}

\section{Participantes}

O estudo foi realizado com profissionais pertencentes a uma das maiores instituições financeiras privadas do Brasil. A organização 
conta com estrutura organizacional tradicional, processos bem definidos, horários rígidos de trabalho e limites claros de autoridade, determinados de acordo com o cargo e a função. Um novo modelo formal de avaliação de desempenho dos funcionários havia sido implantado pouco antes da realização da pesquisa, com base em competências e atendimento de objetivos e metas, objetivando orientar decisões de carreira.

Participaram da pesquisa, em sua etapa quantitativa, 126 profissionais. Todos ocupavam, no período no qual a pesquisa foi realizada, posições de média e alta gestão, com cargos de coordenador $(29 \%)$, gerente $(43 \%)$, superintendente $(25 \%)$ e diretor $(3 \%)$. Quanto ao perfil demográfico, $85 \%$ dos respondentes tinham entre 31 e 50 anos de idade, $71 \%$ haviam cursado pós-graduação e $18 \%$ haviam cursado mestrado. A maioria dos profissionais (82\%) era casada, e $68 \%$ tinham filhos. Deve-se destacar que $25 \%$ dos participantes possuíam mais de 20 anos de atuação no banco; 9\% de 15 a 20 anos; 53\% tinham de 5 a 15 anos de atuação; e um pequeno contingente $(13 \%)$ possuía até 5 anos de atuação na organização. Trata-se, portanto, de uma amostra de profissionais em geral experientes e já socializados na cultura da organização.

Tabela 1

Áreas Pesquisadas

\begin{tabular}{lll}
\hline Área & $\begin{array}{c}\text { Número de } \\
\text { funcionários }\end{array}$ & Descrição
\end{tabular}

Atendimento

Pessoa Física

3.000

Comercial

Pessoa Física

40.000

Crédito

e Cobrança

Pessoa Física

Jurídico

1.200

Modelagem

e Riscos

Recursos

Humanos

1.500

Tecnologia

6.000
Área composta por centrais de atendimento telefônico para clientes do banco e gerentes de agências

Área composta pelas agências, que contam com a equipe comercial do banco e são responsáveis pelo contato direto com o cliente

Área dedicada à definição e operacionalização das estratégias de concessão de crédito e de recuperação de dívidas em atraso

Área administra as questões legais do banco. É responsável por aplicar o direito bancário de forma a orientar as unidades de negócio

Área de apoio, que desenvolve e atualiza os modelos estatísticos utilizados pelas unidades de negócio e que gerencia a posição consolidada de risco do banco

Área na qual se encontram os processos relacionados ao ciclo gestão de pessoas: seleção, contratação, gestão de carreira, remuneração, avaliação de desempenho, desenvolvimento etc.

Área responsável pelo desenvolvimento e manutenção de todos os sistemas de informação e pela infraestrutura correspondente
Alto nível de padronização, divisão rígida das tarefas, foco na eficiência e alta amplitude de controle

Alto nível de padronização e hierarquização; autonomia limitada; separação entre planejamento e execução

Alto nível de padronização nas mesas de crédito e centrais de cobrança; alto grau de informalidade e autonomia nas equipes de política de crédito e cobrança

Área possui departamentos de suporte com processos padronizados; advogados que representam o banco nos tribunais atuam com maior autonomia e flexibilidade

Alto grau de flexibilidade e baixo grau de disciplina e controle; atividades de planejamento e execução realizadas pelas mesmas equipes

Alto grau de padronização e rotinização das tarefas; atividades de planejamento e execução realizados por equipes diferentes

Ampla autonomia; baixa hierarquização; atividades de planejamento e execução realizadas pelas mesmas equipes 
$\mathrm{Na}$ etapa qualitativa, participaram 11 profissionais que também haviam respondido ao questionário da etapa anterior. Procurouse manter um perfil amostral similar, embora a amostragem tenha sido por conveniência. Os participantes se distribuíram da seguinte forma: dois eram da área de Modelagem e Riscos (um homem com idade entre 25-30 anos, matemático; uma mulher com idade entre 40-45 anos, economista); dois da área Jurídica (um homem e uma mulher com idade entre 35-40 anos, ambos advogados); dois de Crédito e Cobrança Pessoa Física (dois homens com idade entre 30-45 anos, engenheiros); dois de Tecnologia (um homem e outra mulher, ambos com idade entre 30-35 anos, engenheiros); um da área de Atendimento Pessoa Física (um homem com idade entre 30-35 anos, engenheiro); um da área Comercial Pessoa Física (um homem com idade entre 30-35 anos); e um de Recursos Humanos (uma mulher com idade entre 30-35 anos, formada em propaganda e marketing).

\section{Instrumentos e Procedimentos}

A primeira etapa da pesquisa utilizou um questionário dividido em três partes: a primeira compreendia um levantamento das informações demográficas; a segunda continha questões sobre a carreira do entrevistado; e a terceira dedicava-se ao levantamento específico sobre atitudes de carreira sem fronteiras. A terceira etapa baseou-se na Boundaryless Career Attitudes Scale (BCAS), desenvolvida por Briscoe, Hall e DeMuth (2006), adaptada e validada para a língua portuguesa por Oliveira et al. (2010) e denominada de Escala de Atitudes de Carreira Sem-fronteiras (EACSF).

$\mathrm{Na}$ versão original, a referida escala apresentava 13 itens, distribuídos em duas subescalas, ambas destinadas a avaliar atitudes de carreira sem fronteiras. A primeira subescala era constituída por oito itens e avaliava a percepção do sujeito sobre sua capacidade de fazer transições de carreira, sendo denominada de Mobilidade Psicológica (MP). A segunda subescala continha cinco itens avaliando a intensidade do interesse em permanecer em uma mesma organização, ou, colocando de outra forma, a percep- ção da capacidade para se efetuar transições de fronteiras - denominada de Mobilidade Física (MF). Na versão brasileira, os autores retiveram dez itens, sendo seis na subescala de MF e cinco na subescala de MP (Oliveira et al., 2010). Foram obtidos bons índices de confiabilidade (alfa $=0,76)$ e das subescalas de MF $($ alfa $=0,79)$ e de MP (alfa $=0,87)$.

Cada um dos 10 itens foi avaliado a partir de uma escala Likert, de 1 ("não me caracteriza") a 5 ("caracteriza-me totalmente"). O questionário foi administrado a partir da Internet, por meio da ferramenta SurveyMonkey. O anonimato e a confidencialidade das repostas foram preservados pelos pesquisadores.

A segunda etapa da pesquisa envolveu a realização de entrevistas semiestruturadas, visando aprofundar a compreensão de questões identificadas na primeira etapa. O roteiro continha questões relacionadas à carreira do entrevistado, envolvendo os seguintes tópicos: (a) descrição de atividades realizadas, visando à contextualização do trabalho; (b) percepção de competências necessárias à realização do trabalho $\mathrm{e}$ ao progresso na carreira - mais especificamente, exploração das competências know why, know how e know whom (baseando-se em DeFillippi \& Arthur, 1994); (c) questões sobre significado do trabalho e satisfação com a própria carreira - baseando-se em Lips-Wiersma e Mcmorland (2006). As entrevistas tinham início com uma breve explicação sobre o objetivo da pesquisa, a menção sobre a confidencialidade das informações e um pedido de autorização para gravação e posterior transcrição e análise. No encerramento, o entrevistado era estimulado a adicionar comentários adicionais que julgasse relevantes e pertinentes ao tema.

A realização da pesquisa contou com a anuência da organização. Foram seguidos todos os procedimentos éticos envolvendo pesquisas com seres humanos, conforme Resolução 196/96 do Conselho Nacional de Saúde (CNS, 1996), tais como anonimato, liberdade de deixar a pesquisa a qualquer momento, garantia de sigilo e tratamento coletivo das informações (não foram consideradas as respostas por indivíduos, mas o conjunto de respondentes). 


\section{Procedimentos de Análise de Dados}

A análise dos dados obtidos pela aplicação da EACSF foi conduzida segundo instruções contidas nos trabalhos de Briscoe et al. (2006) e de Oliveira et al. (2010). O primeiro passo consistiu em averiguar as características psicométricas da EACSF para a amostra utilizada neste estudo. Assim, primeiramente foi conduzida uma inspeção descritiva da base de dados. Em particular, buscou-se observar se a matriz dos dados era fatorável, o que se confirmou, na medida em que o Teste de Bartlett revelou-se significativo, $X_{(45)}^{2}=442,947, p<0,001$.

A amostra também se mostrou adequada, uma vez que obteve-se um moderado índice Kaiser-Meyer-Olkin (KMO) de 0,74, praticamente o mesmo $(0,79)$ encontrado na fase do estudo piloto de Oliveira et al. (2010). Uma vez estabelecida a estrutura fatorial e assegurada sua consistência interna (avaliada pelo alfa de Cronbach), o passo seguinte foi investigar as associações entre os fatores da EACSF e as demais variáveis introduzidas no estudo. Para isso, foram utilizadas técnicas de comparação entre médias (ANOVA) e de correlação (teste de correlação de Pearson).

O processo de análise das informações das entrevistas (dados qualitativos) foi conduzido tendo como base as técnicas de análise temática de conteúdo (Bardin, 1977). As entrevistas foram transcritas e buscou-se organizar seu conteúdo em função de dimensões pré-analíticas adotadas neste estudo (conforme apoio no referencial teórico) e presentes no roteiro de entrevista. Além disso, buscou-se também identificar temas comuns entre as entrevistas, comparando-as entre si.

\section{Resultados}

\section{Apresentação dos Dados Quantitativos}

Primeiramente, são reportados os resultados da análise fatorial realizada com os dados obtidos por meio da aplicação da EACSF. Seguindo a recomendação dos autores da escala original (Briscoe et al., 2006) e dos autores da versão traduzida e adaptada para o português (Olivei- ra et al., 2010), foram solicitados dois fatores, utilizando o método dos componentes principais (PCA), rotação oblíqua (oblimin), critério de carga fatorial maior que 0,40 para retenção dos itens, e $p<0,05$.

Como se pode constatar pelas informações apresentadas na Tabela 2, a EACSF manteve seus dois fatores originais (e seus dez itens) com a presente amostra de profissionais do setor financeiro. Todos os pesos fatoriais estão acima do ponto de corte estipulado $|\lambda>0,40|$. No total, os dois fatores explicam $55,41 \%$ da variância dos dados, e apresentam de moderados a bons índices de consistência interna (alfa de Cronbach) nas subescalas $(\mathrm{MF}=0,85 ; \mathrm{MP}=0,74)$, e também no global da escala (alfa $=0,74)$. As médias fatoriais revelam-se moderadamente altas: 3,89 para MF e 3,03 para MP. Essas médias indicam que os profissionais investigados tendem, no geral, a ter preferência por atividades de trabalho que lhes permitam ter contato com pessoas, contextos e organizações diferentes. Sugerem também que os participantes buscam, ativamente, oportunidades de trabalho que lhes possibilitem alcançar seus objetivos e suas preferências de mobilidade.

Uma vez realizada a análise fatorial e assegurada a consistência psicométrica da estrutura original do instrumento com a amostra atual, foram então conduzidas análises para comparar as médias dos dois fatores (ANOVA, com teste post-hoc de Tukey) com as variáveis: área de atuação dentro da organização, cargo e formação do participante; e análises de correlação (correlação de Pearson) desses mesmos dois fatores com as variáveis: número de mudanças de área dentro da organização, e número de mudanças voluntárias de emprego ao longo da carreira. Todas as diferenças significativas são reportadas sob $p<0,05$.

No que diz respeito à comparação entre médias (ANOVA), foram identificadas relações significativas entre o fator Mobilidade Física e área de atuação, embora com um tamanho de efeito muito pequeno $\left(F_{[6,119]}=2,74 ; p<0,01 ; \omega\right.$ $=0,07)$. Profissionais da área Comercial apresentam médias significativamente maiores nesse fator do que os profissionais da área de Crédito e cobrança $(\Delta M=0,59)$; e profissionais de Tecno- 
Tabela 2

Carga Fatorial dos Itens da BCAS, Índices de Confiabilidade e Média dos Fatores

Fatores

Itens

MF MP

1. Eu gosto de atividades que requeiram que eu trabalhe fora da organização.

2. Eu gosto de atividades que requeiram que eu trabalhe além de meu próprio departamento.

3. Eu gosto de trabalhar com pessoas fora da minha organização (com clientes, fornecedores, parceiros, órgãos reguladores).

4. Eu gosto de trabalhos que requeiram que eu interaja com pessoas em várias organizações diferentes.

5. No passado busquei oportunidades que permitem que hoje eu trabalhe fora da organização.

6. Eu me sinto revigorado em novas experiências e situações

7. Eu me sentiria muito desorientado se não pudesse trabalhar para a organização na qual trabalho atualmente.

8. Eu prefiro permanecer em uma organização com a qual estou familiarizado a buscar oportunidades em outro local de trabalho.

9. Se a organização para a qual trabalho oferecesse empregos que durassem a vida toda, eu jamais desejaria trabalhar para outras organizações.

10. O meu ideal de carreira seria trabalhar em uma única organização.

Variância explicada

Média (geral: 3,$65 ; D P=0,77$ )

Desvio-padrão

Alfa de Cronbach

0,74

Nota . Mobilidade Física = MF, Mobilidade Psicológica = MP. Os itens que compõem o fator MF foram invertidos para análise . As médias desse fator referem-se à preferência ou atitude de mudança em relação à organização atual.

logia apresentam médias mais elevadas do que os de Crédito e cobrança $(\Delta M=0,57)$. Quanto à Mobilidade Psicológica, também se verificaram diferenças significativas com a área de atuação, mas com um tamanho do efeito modesto $\left(F_{[6,119]}=3,84 ; p<0,01 ; \omega=0,12\right)$. Nesse caso, profissionais de Tecnologia apresentaram médias significativamente mais elevadas do que os de Crédito e cobrança $(\Delta M=0,81)$ e Recursos humanos $(\triangle M=0,82)$.

Quanto às demais análises realizadas, a única associação significativa identificada entre os dois fatores de atitudes de carreira sem fronteira e as variáveis do estudo ocorreu entre tempo de organização e Mobilidade Física $(r=-0,32 ; p$ $<0,01$ - bicaudal). Disso se pode deduzir que, quanto menos tempo possui o profissional na organização em tela, mais propenso ele estará a trocar de emprego (correlação negativa).

\section{Apresentação dos Dados Qualitativos}

Nesta subseção, serão apresentadas as categorias temáticas identificadas pela análise de conteúdo. O propósito desta etapa foi compreender o contexto de trabalho dos participantes, sua experiência em relação às competências essen- 
ciais da carreira sem fronteiras e sua visão sobre o próprio papel no desenvolvimento da carreira.

Competências Know Why. As competências know-why, conforme indicado anteriormente, referem-se às motivações para a realização da atividade. $\mathrm{O}$ fato de os gestores exercerem um trabalho com sentido é relevante para o desenvolvimento das competências know why (Lacombe, 2005). Estas, por sua vez, evidenciam os motivos, os interesses e as expectativas dos gestores frente à carreira e o nível de identificação com o trabalho e com a organização.

De forma quase unânime, os entrevistados demonstram grande interesse por desafios no trabalho e pela expansão de seus conhecimentos. Eles declararam preferir estar em um ambiente desafiador, no qual novos projetos surjam constantemente, exigindo diferentes habilidades e permitindo seu desenvolvimento. Atividades rotineiras e monótonas não são vistas como oportunidades de aprendizado. De acordo com um entrevistado:

Os desafios são muito legais, quando conseguimos atingi-los a sensação de superação é muito grande. Além disso, a dinâmica do negócio bancário é bem interessante, pois não permite que o trabalho se torne estável e monótono. Você não atua só nos aspectos estritamente jurídicos, você tem relacionamento com muitas áreas, precisa aprender sobre a parte financeira, sobre liderança, gestão de pessoas. O aprendizado para mim é muito motivador. (Gerente do Jurídico)

Os entrevistados também apontaram a gestão de pessoas como um tema de interesse. A liderança da equipe pode proporcionar status e poder, além de gerar realização no gestor, por meio do desenvolvimento dos indivíduos. Segundo um entrevistado:

"Eu percebi que meu grande sonho, meu objetivo de carreira é me consolidar como um líder, um gestor, independente da atividade que eu faça. Hoje para mim, liderar grupos cada vez maiores é uma motivação e um objetivo" (Superintendente de Crédito e Cobrança).

Deste modo, as competências know why levantadas sugerem proximidade com as ca- racterísticas de carreiras sem fronteira. Em nenhum momento foram citadas motivações que se aproximassem das características de carreira tradicional, como estabilidade ou segurança no trabalho.

Competências Know How. As competências know how, conforme indicado anteriormente, compreendem as habilidades e os conhecimentos necessários para o bom desempenho do trabalho. Para desenvolver as competências know how é importante acompanhar as mudanças e cuidar da adaptação a elas.

$\mathrm{Na}$ pesquisa de campo, os entrevistados revelaram as habilidades indispensáveis para o desempenho do trabalho dentro da organização. A competência indicada por eles como prioritária foi a facilidade de relacionamento, que envolve o trabalho em equipe e a construção de parcerias. Conforme declarou um entrevistado:

"As pessoas precisam ter facilidade de relacionamento, tem que saber se comunicar muito bem, traduzir a linguagem técnica para uma linguagem mais amigável. É essencial ter parceria com outras áreas" (Gerente de Tecnologia).

A comunicação também se mostra como uma competência requerida para os entrevistados, principalmente para gestores de grandes equipes, caso das áreas de Atendimento, Comercial e Crédito, por exemplo. Os gestores indicaram que é importante saber se comunicar com públicos diferentes e usar linguagem adequada conforme a audiência. Segundo um entrevistado:

A linguagem para se reportar a um diretor é uma, para lidar com uma equipe técnica é outra e para usar em uma central de atendimento é uma terceira, e bem diferente. Fiz uma campanha motivacional logo que cheguei baseada no delta de desempenho dos atendentes e foi um fracasso porque não sabiam o que significava delta. (Gerente de Atendimento)

Outras competências apontadas pelos entrevistados foram visão sistêmica e raciocínio lógico, que tornariam possível compreender o cenário e analisar situações de forma estruturada, tomando decisões racionais e consistentes com a 
estratégia da empresa. Para a carreira sem fronteiras, estas competências são essenciais, pois permitem ao indivíduo migrar de uma organização para outra.

Competências Know Whom. As competências know whom, conforme indicado anteriormente, referem-se à rede de relacionamento na vida profissional. Nas entrevistas foi também possível evidenciar tais competências. Os entrevistados reconheceram o papel das relações interpessoais na carreira. Para eles, as redes de relacionamento que os indivíduos estabelecem no ambiente de trabalho, em cursos ou em qualquer outra situação que permita a troca de experiências profissionais, aumentam as chances de novas oportunidades de trabalho surgirem no futuro. A importância das redes de relacionamentos ficou clara nas entrevistas realizadas. No entanto, alguns entrevistados perceberam a distinção entre redes próprias de relacionamento e redes da empresa na qual trabalham. De fato, tal distinção é descrita na literatura científica (eg., Lacombe, 2005). Conforme declarou um dos entrevistados:

O nome do banco é fantástico. Quando falo que trabalho aqui, ganho uma projeção muito grande. Por outro lado, meu nome é único no mercado, tenho uma chance de me apresentar e eu não posso errar. $O$ banco me abre as portas e eu tenho a responsabilidade de fazer a coisa certa. Assim mantenho um relacionamento de alto nivel com juizes e desembargadores. (Gerente do Jurídico)

Por outro lado, apesar da importância das relações interpessoais para a carreira e do reconhecimento por parte dos gestores quanto às oportunidades geradas pelas redes de relacionamento, o esforço para manter tais redes não parece ser claro. A análise das entrevistas indica que as trocas de emprego acontecem por convite de antigos gestores, porém ainda são raros os encontros destinados à troca de informação e experiência, e ao fortalecimento das redes próprias de relacionamento.

Responsabilidade pela Carreira. Nos últimos anos, na instituição financeira estudada, assim como em muitas outras grandes empresas, a premissa de que a responsabilidade pela carreira é essencialmente do próprio indivíduo foi fortemente disseminada. Significativamente, para $64 \%$ dos entrevistados a responsabilidade pela carreira é deles próprios. Conforme revelaram, é dever de cada um analisar sua satisfação no trabalho e, caso não esteja feliz, sair e encontrar algo que traga realização pessoal. Segundo um entrevistado:

Eu acho que cada um é responsável por sua carreira. No limite, se eu não estou feliz ou não estou tendo retorno, reconhecimento, eu vou buscar em outro lugar. Se eu fico, eu fico porque eu quero, se eu saio, eu saio porque eu quero. (Gerente do Jurídico) Outro entrevistado complementou: A instituição é muito maior que o indivíduo e ela não pode tomar decisões pensando pessoa a pessoa. O indivíduo tem capacidade de tomar decisóes e isso o ajuda conciliar a carreira com o que of faz feliz efetivamente. Quando a pessoa assume realmente a gestão da carreira, ela para de justificar as coisas, de colocar a culpa nos outros. (Superintendente de Crédito e Cobrança)

Apesar de muitos entrevistados afirmarem que a responsabilidade pela carreira é do indivíduo, apenas dois deles parecem ter assumido efetivamente esse papel. No inicio de suas vidas profissionais, eles definiram etapas de carreira e um objetivo final, e hoje demonstram monitorar seus passos de forma estruturada e consistentes.

Por outro lado, $36 \%$ dos entrevistados indicaram outros fatores que influenciam no desenvolvimento da carreira. Alguns entrevistados acreditam que a organização possui sua parcela de responsabilidade, à medida que pode proporcionar ao funcionário um ambiente desafiador, no qual ele consiga se desenvolver. Consideram também ser papel da organização avaliar as condições do profissional para atingir seus objetivos e o orientar quanto aos caminhos a serem percorridos.

\section{Discussão}

Nesta seção, são destacadas três questões que emergiram dos resultados da pesquisa de campo. A primeira refere-se a um aparente pa- 
radoxo: a forte presença de atitudes de carreira sem fronteiras em uma organização tradicional. A segunda refere-se às diferenças entre áreas. $\mathrm{E}$ a terceira questão refere-se à relação entre tempo de trabalho na empresa e atitudes de carreira sem fronteiras. Essas três questões retomam os objetivos centrais desta investigação.

Ambas as etapas desta pesquisa indicam que os entrevistados apresentam atitudes de carreira sem fronteiras. Entretanto, tais profissionais trabalham para uma organização tradicional, onde a hierarquia é rígida e há obstáculos para a mobilidade. Assim, os gestores possuem atitudes de carreira sem fronteiras, porém parecem aceitar conviver com padrões de carreiras organizacionais. Como explicar tal paradoxo?

Uma primeira reflexão sobre esse aparente paradoxo pode ser encontrada nas conclusões do estudo de Gerber et al. (2009). Nele, esses autores observam que orientações de carreira consideradas "novas" coexistem com orientações "antigas". Quer dizer, não haveria, no nível dos valores e das práticas cotidianas, uma ruptura definitiva entre esses modelos. Primeiro, porque, a despeito das alardeadas mudanças no mundo do trabalho, existem ainda zonas de estabilidade provisórias - como é o caso da organização em tela, considerando que $63 \%$ dos profissionais aqui investigados possuem entre 10 e mais de 20 anos de vínculo empregatício "tradicional".

Ademais, como observam Veloso e Dutra (2011), também a propósito de experiências de carreira sem fronteiras em uma instituição bancária, mais importante do que a disposição para mobilidade física é também a psicológica - o que parece fazer a diferença entre uma atitude mais próxima da carreira organizacional em sentido estrito (por exemplo, emprego para a vida toda, decisões de carreira centradas na organização), e uma atitude de carreira sem fronteiras (por exemplo, mobilidade, responsabilidade pelo próprio desenvolvimento; Tams \& Arthur, 2010). À primeira vista, portanto, o paradoxo pode ser apenas aparente, pois a convivência de distintas orientações de carreira não parece incompatível - paradoxo que pode ser, em última instância, entre agência e estrutura, tal como discutido numa das linhas de debate presente nos estudos sobre carreira e citada na introdução (Peiperl \& Arthur, 2000).

Uma segunda reflexão mergulha nas conclusões de outro estudo, também apresentado na introdução e tendo como contexto o setor bancário. Nele, Oltramari e Lorenzato (2012) destacam que uma possível "fronteira" para as carreiras sem fronteiras de gerentes bancários é a família. Embora, na análise quantitativa aqui empreendida, não se tenha verificado diferenças significativas em função de o profissional ser ou não casado, e ter ou não filhos, é possível afirmar que esse aspecto pode ter, em alguma medida, favorecido a manutenção do vínculo com a organização, a despeito de haver forte tendência a atitudes de carreira sem fronteiras - talvez não se tenha identificado relações significativas, pois a maior parte da amostra (82\%) é casada e tem filhos (68\%). Corroborando achados da literatura que destacam os condicionantes contextuais da carreira sem fronteiras (e.g., Dany, 2003; Duberley, Mallon, \& Cohen, 2006), pode-se pensar que a organização, pela sua posição no mercado, oferece oportunidades a seus profissionais (incluindo mobilidade intraorganizacional).

Portanto, é também possível pensar no supracitado paradoxo a partir da compreensão do contrato psicólogo estabelecido com a organização (Rousseau, 1995). Pelas evidências aqui reunidas, há suporte em afirmar que os profissionais têm consciência de que há uma transação mutuamente favorável entre eles e a organização. Eles analisam alternativas, trocas e escolhas propostas e tomam decisões em relação às suas carreiras. A organização, ciente de que recompensas diferenciadas contribuem para um elo mais forte entre empregado e empresa, cria mecanismos para garantir a retenção dos profissionais. Um exemplo significativo desse tipo de mecanismo é o subsídio a cursos de pós-graduação, atrelado a um período de carência para saída do funcionário. Tal sistema permite que o indivíduo desenvolva competências transportáveis, porém faz com que aceite a imposição do vínculo com a organização durante o período de carência. Esse e diversos outros mecanismos permite a convivência de atitudes de carreira sem fronteiras em uma organização tradicional. 
No que diz respeito às diferenças entre áreas, a etapa quantitativa revelou alguns aspectos importantes. A área de Tecnologia obteve média significativamente maior na escala de atitudes de carreira sem fronteiras quando comparada a outras duas áreas (Crédito e cobrança e Recursos Humanos). De forma complementar, e coerente com os resultados da parte quantitativa, os entrevistados da área de Tecnologia mostraram desprendimento da organização, afirmando que se mantêm na organização enquanto "concordam com a cultura", com o direcionamento dos negócios e com o contrato psicológico entre empresa e funcionários.

Tal resultado é coerente com uma tendência mais ampla, que envolve profissões ligadas às tecnologias de informação e comunicação (Allvin, 2011; Saxenian, 1996). De fato, tais tecnologias ganharam proeminência e valor estratégico para as empresas. São baseadas em conhecimento especializado, frequentemente hermético, dominado por grupos específicos de profissionais, os quais desenvolvem competências facilmente transportáveis, mantêm redes externas de relacionamento e têm alta empregabilidade e mobilidade (Lopes \& Silva, 2009). Essas características moldam uma cultura profissional que favorece as atitudes de carreira sem fronteiras, mesmo entre funcionários que atuam dentro de grandes empresas, como é o caso da organização estudada.

É preciso, todavia, ressaltar que o tamanho do efeito das supracitadas diferenças de médias entre áreas foi pequeno. Quer dizer, embora significativa, tais diferenças podem não revelar um expressivo significado prático. De todo modo, a simples existência dessas diferenças, ainda que pequenas, sugere a ocorrência do fenômeno apontado na introdução, concernente à possibilidade de uma carreira sem fronteiras ser plausível de existir dentro de grandes organizações, mesmo com os dilemas derivados desse fenômeno, tais como apontados por Oltramari e Lorenzato (2012).

Por fim, a etapa quantitativa da pesquisa revelou uma maior propensão, em termos de atitudes de carreira sem fronteiras, entre profissionais com menor tempo de trabalho na empresa. Natu- ralmente, tal condição está também associada à idade dos profissionais, o que leva a estabelecer como hipótese que profissionais mais jovens tendem a exibir atitudes mais fortes de carreira sem fronteiras. Isso é convergente com outros achados similares presentes na literatura (e.g., Currie et al., 2006). Ademais, aspectos contextuais podem ajudar a explicar esse resultado. Primeiro, os jovens, pela sua própria condição (por exemplo, solteiros), podem ter condições mais favoráveis de mobilidade (física e psicológica); segundo, eles podem estar mais dispostos a atitudes exploratórias de carreira (e.g., Super, Savickas, \& Super, 1996), o que implica em maior disposição à mobilidade. Isso pode trazer algumas implicações para os sistemas de gestão das organizações, como se destaca na próxima seção.

\section{Conclusão}

O objetivo deste estudo foi investigar as atitudes dos indivíduos frente à carreira dentro de uma grande instituição financeira brasileira, com base no modelo de carreira sem fronteiras. Para isso, metodologicamente, utilizou-se um desenho misto, quantitativo e qualitativo. Com base na pesquisa de campo realizada, foi possível identificar atitudes de carreira sem fronteiras nos indivíduos da organização estudada.

A tendência para carreiras sem fronteiras pode ser observada por meio das entrevistas, nas quais foram identificadas as competências know why, know how e know whom. Os entrevistados apresentam competências know why desenvolvidas, conhecendo seus interesses e motivações. Além disso, parecem investir nas competências know how, mostrando saber quais são as habilidades necessárias para desenvolver o trabalho. Tais habilidades - construção de parceria, negociação, gestão de pessoas, comunicação e liderança - podem ser considerada transportáveis, ou seja, utilizadas em outras organizações. Finalmente, quanto às competências know whom, os gestores reconhecem as oportunidades criadas pelas redes de relacionamento por experiência própria, porém se mostram poucos dispostos a investir tempo na construção e manutenção dessas redes. 
Uma das razões para os entrevistados desenvolverem atitudes de carreira sem fronteiras parece ver da busca de sentido no trabalho. Nas entrevistas, os gestores indicaram autonomia e liberdade para decidir como fatores que fazem o trabalho ter sentido. De fato, tais características estão presentes na literatura sobre o significado do trabalho e também na literatura sobre carreiras sem fronteiras (e.g., Lips-Wiersma \& Mcmorland, 2006; Meaning of Work International Research Team [MOW], 1987).

Paradoxalmente, ainda que a tendência geral aponte no sentido de atitudes de carreira sem fronteiras, muitos entrevistados mantêm forte vínculo com a organização, guiam suas carreiras pelas oportunidades oferecidas pela empresa, entendem o progresso como a escalada na hierarquia e responsabilizam o acaso pela evolução ou pela estagnação na carreira. Assim, apesar de os indivíduos terem manifestado atitudes de carreira sem fronteiras, não se pode afirmar que tal manifestação corresponde a um "tipo ideal" de carreira sem fronteiras. $\mathrm{O}$ contexto encontrado na pesquisa parece representar uma situação híbrida, de coexistência de distintas atitudes face à carreira. Foi possível verificar diferentes níveis de atitudes de carreira sem fronteiras presentes entre os entrevistados e entre áreas.

É preciso destacar que este trabalho foi conduzido de forma exploratória. Acredita-se que tenha trazido uma contribuição para o avanço do estudo das carreiras no Brasil, à medida que retratou e analisou as atitudes de gestores de uma grande organização local em relação às carreiras sem fronteiras. No entanto, apresenta algumas limitações, as quais podem constituir oportunidades para futuras pesquisas. A primeira refere-se a sua realização em uma única organização de grande porte. A segunda limitação refere-se a sua realização apenas com gestores. Seria proveitoso ampliar a pesquisa para outros extratos profissionais dentro da organização. Além disso, considera-se desejável conduzir pesquisas que pudessem aprofundar o entendimento das três questões tratadas na seção anterior: a forte presença de atitudes de carreira sem fronteiras em uma organização tradicional; as diferenças entre áreas; e a relação entre tempo de trabalho na empresa e atitudes de carreira sem fronteiras. Tais questões podem ser do interesse tanto de pesquisadores do campo das carreiras, quanto de profissionais de recursos humanos, interessados em compreender melhor o processo de transição em curso.

Este trabalho traz três contribuições práticas. Primeiro, o trabalho realizado trouxe a tona que a convivência, em uma mesma organização, de profissionais e grupos com níveis diferentes de atitudes de carreira sem fronteiras gera tensões. Essas tensões derivam de diferentes perspectivas e expectativas sobre desenvolvimento, crescimento profissional e mobilidade. Tal condição deve ser objeto de atenção dos gestores. Segundo, a pesquisa revelou que profissionais que têm maior interação com o mercado de trabalho e com colegas de outras empresas (como, por exemplo, no caso da área de tecnologia), apresentam níveis superiores de atitudes de carreira sem fronteiras. Tal condição deve também ser objeto de atenção dos gestores. Terceiro, os resultados revelam a complexidade e alguns paradoxos relacionados às carreiras sem fronteiras. Compreender tal condição é essencial para gestores em geral e para gestores de recursos humanos em especial. A realidade das carreiras sem fronteiras traz implicações relevantes sobre o vínculo entre profissionais e empresas.

\section{Referências}

Allvin, M. (2011). New rule of work: Exploring the boundaryless job. In K. Naswall, J. Hellgren, \& M. Sverke (Eds.), The individual in the changing working life (pp. 19-45). Cambridge, UK: Cambridge University Press.

Arthur, M. B. (1994). The boundaryless career: A new perspective for organizational inquiry. Journal of Organizational Behavior, 15(4), 295306. doi:10.1002/job

Arthur, M. B., Hall, D. T., \& Lawrence, B. S. (1989). The handbook of career theory. Cambridge, UK: Cambridge University Press.

Arthur, M., Inkson, K., \& Pringle, J. K. (1999). The new careers. Thousand Oaks, CA: Sage.

Arthur, M. B., \& Rousseau, D. M. (1996). The boundaryless career: New employment principle 
for a new organizational era. Oxford, UK: Oxford University Press.

Balassiano, M. (2006). Gestão de carreiras: Dilemas e perspectivas. São Paulo, SP: Atlas.

Bardin, L. (1977). Análise de conteúdo. Lisboa, Portugal: Edições 70.

Baruch, Y. (2004). Transforming careers: From linear to multidirectional careers paths. Career Development International, 9(1), 58-73. doi: $10.1108 / 13620430410518147$

Baruch, Y. (2006). Career development in organizations and beyond. Human Resource Management Review, 16(2), 125-138. doi:10.1016/j. hrmr.2006.03.002

Bastos, V. B., \& Andrade, A. E. (2002). Comprometimento com o trabalho: Padrões em diferentes contextos organizacionais. Revista de Administração de Empresas, 42(2), 31-41. doi:10.1590/ S0034-75902002000200003

Beck, U. (2000). The brave new world of work. London: Polity.

Bendassolli, P. (2009). Recomposição da relação sujeito-trabalho nos modelos emergentes de carreira. Revista de Administração de Empresas, 49(4), 387-400. doi:10.1590/S003475902009000400003

Bendassolli, P. F., \& Wood, T., Jr. (2010). O paradoxo de Mozart: Carreiras nas indústrias criativas. Organizações \& Sociedade, 17, 259-277. doi:10.1590/S1984-92302010000200002

Borgen, W. A., Amundson, N. E., \& Reuter, J. (2004). Using portfolios to enhance career resilience. Journal of Employment Counseling, 41(2), 5059. doi:10.1002/j.2161-1920.2004.tb00878.x

Briscoe, J., Hall, D., \& DeMuth, R. (2006). Protean and boundaryless careers: An empirical exploration. Journal of Vocational Behavior, 69, 30-47. doi:10.1016/j.jvb.2005.09.003

Chanlat, J. F. (1995). Quais carreiras e para qual sociedade? Revista de Administração de Empresas, 35(6), 67-75. doi:10.1590/S003475901995000600008

Colakoglu, S. N. (2011). The impact of career boundarylessness on subjective career success: The role of career competencies, career autonomy, and career insecurity. Journal of Vocational Behavior, 79(1), 47-59. doi:10.1016/j. jvb.2010.09.011
Conselho Nacional de Saúde. (1996). Diretrizes e normas regulamentadoras de pesquisas envolvendo seres humanos: Resolução No196/96. Recuperado em http://pfdc.pgr.mpf.mp.br/atuacao-e-conteudos-de-apoio/legislacao/saude/ resolucoes/Resolucao_CNS_196.1996

Currie, G., Tempest, S., \& Starkey, K. (2006). New careers for old? Organizational and individual responses to changing boundaries. International Journal of Human Resource Management, 17(4), 755-774. doi:10.1080/09585190600581733

Dany, F. (2003). Free agents and organizations. International Journal of Human Resource Management, 14(5), 821-838.

DeFillippi, J. R., \& Arthur, M. B. (1994). The boundaryless career: A competency-based perspective. Journal of Organizational Behavior, 15(4), 30724. doi:10.1002/job.4030150403

Dubar, C., \& Tripier, P. (2005). Sociologie des professions. Paris: Armand Colin.

Duberley, J., Mallon, M., \& Cohen, L. (2006). Exploring career transitions: Accounting for structure and agency. Personnel Review, 35(3), 281296. doi:10.1108/00483480610656694

Dutra, J. S. (2009). Gestão de carreiras na empresa contemporânea. São Paulo, SP: Atlas.

Eby, L. T., Butts, M., \& Lockwood, A. (2003). Predictors of success in the era of the boundaryless career. Journal of Organizational Behavior, 24, 689-708.

Fontenelle, I. (2007). A autogestão de carreira chega à escola de administração: O humano se tornou capital? Organizações \& Sociedade, 14(43), 7189. doi:10.1590/S1984-92302007000400004

Forret, M. L., Sullivan, S. E., \& Mainiero, L. A. (2010). Gender role differences in reactions to unemployment: Exploring psychological mobility and boundaryless careers. Journal of $\mathrm{Or}$ ganizational Behavior, 31, 647-666. 10.1002/ job. 703

Gerber, M., Wittekind, A., Grote, G., Conway, N., \& Guest, D. (2009). Generalizability of career orientations: A comparative study in Switzerland and Great Britain. Journal of Occupational and Organizational Psychology, 82(4), 779-801. doi:10.1348/096317909X474740

Grzeda, M. M. (1999). Re-conceptualizing career change: A career development perspective. 
Career Development International, 4(6), $305-$ 311. doi:10.1108/13620439910287979

Gunz, H., \& Peiperl, M. (2007). Handbook of career studies. London: Sage.

Hall, D. T. (1976). Career in organizations. Glenview, IL: Scott Foresman.

Hall, D. T. (2002). Careers in and out of organizations. Thousand Oaks, CA: Sage.

Hall, D. T. (2004). The protean career: A quartercentury journey. Journal of Vocational Behavior, 65(1), 1-13. doi:10.1016/j.jvb.2003.10.006

Inkson, K. (2007). Understanding careers. London: Sage.

Inkson, K., \& Baruch, Y. (2009). Organizational careers. In S. R. Clegg \& C. L. Cooper (Eds.), The Sage handbook of organizational behavior (pp. 209-223). Thousand Oaks, CA: Sage.

Inkson, K., \& Parker, P. (2005). Boundaryless career and the transfer of knowledge: A "Middle Earth" perspective. Higher Education Police, 18, 313-325. doi:10.1057/palgrave.hep.8300093

Kilimnik, Z. M. (Ed.). (2011). Transformações e transições nas carreiras. Rio de Janeiro, RJ: Qualitymark.

Kilimnik, Z. M., Sant'Anna, A. S., \& Castilho, I. V. (2007). Carreiras em transformação e seus paradoxais reflexos nos indivíduos. In D. T. R. Barros, M. T. Lima, \& R. Escalda (Eds.), Escolha e inserção profissionais (pp. 21-42). São Paulo, SP: Vetor.

Lacombe, B. (2005). O modelo da carreira sem fronteiras no contexto organizacional: Pesquisando a carreira do professor universitário no Brasil (Relatório No. 08). Brasília, DF: Fundação Getúlio Vargas.

Lips-Wiersma, M. S., \& Mcmorland, J. (2006). Finding meaning and purpose in boundaryless careers. Journal of Humanistic Psychology, 46(2), 147-167. doi:10.1177/0022167805283776

London, M., \& Bray, D. W. (1984). Measuring and developing young manager's career motivation. Journal of Management Development, 3(3), 3-25.

Lopes, A. L., \& Silva, J. R. (2009). Expectativas profissionais no discurso de terceirizados em TI. Revista de Administração Eletrônica, 8(2), 1-24. doi:10.1590/S1676-56482009000200002
McMahon, M. L., \& Patton, W. A. (2006). Career counselling: Constructivist approaches. London: Routledege.

Meaning of Work International Research Team. (1987). The meaning of working. New York: Academic Press.

Mendenhall, M. E., Kuhlmann, T. M., \& Stahl, G. K. (2001). Developing global business leaders: Policies, processes and innovations. New York: Quorum Books.

Oliveira, M., Zanon, C., Silva, I., Pinhatti, M., Gomes, W., \& Gauer, G. (2010). Validação da versão brasileira da Escala de Atitudes de Carreiras Sem Fronteiras. Arquivos Brasileiros de Psicologia, 62(3), 106-114.

Oltramari, A., \& Lorenzato, S. (2012). Dilemas da carreira sem fronteira: Um estudo de caso com gerentes bancários. Revista de Carreiras e Pessoas, 2(3), 2-19.

Peiperl, M. A., \& Arthur, M. B. (2000). Topics for conversation: Career themes old and news. In M. A. Peiperl, M. B. Arthur, R. Goffee, \& T. Morris (Eds.), Career frontiers: New conceptions of working lives (pp. 1-20). Oxford, UK: Oxford University Press.

Pringle, J. K., \& Mallon, M. (2003). Challenges for the boundaryless career odyssey. International Journal of Human Resource Management, 14(5), 839-853.

Rousseau, D. (1995). Psychological contracts in organizations. London: Sage.

Savickas, M. (2009). Revitalising vocational psychology and energising the study of career: A way forward. In A. Collin \& W. Patton (Eds.), Vocational psychological and organizational perspectives on career (pp. 197-208). Rotterdam, Holland: Sense.

Saxenian, A. L. (1996). Beyond boundaries: Open labor markets and learning in Silicon Valley. In M. Arthur \& D. M. Rousseau (Eds.), The boundaryless career (pp. 23-39). New York: Oxford University Press.

Scalabrin, A. C. (2008). Carreiras sem fronteiras $e$ trajetórias descontínuas: Um estudo descritivo sobre decisões de opt-out (Dissertação de mestrado, Faculdade de Economia, Administração e Contabilidade, Universidade de São Paulo, SP, Brasil). 
Stickland, R. (1996). Career self-management. International Journal of Work and Organizational Psychology, 5(4), 583-596.

Sullivan, S. E. (1999). The changing nature of careers: A review and research agenda. Journal of Management, 25(3), 457-484. doi:10.1177/014920639902500308

Super, D. E., Savickas, M. L., \& Super, C. M. (1996). The life-span, life-space approach to careers. In D. Brown \& L. Brooks (Eds.), Career choice and development (pp. 121-178). San Francisco, CA: Jossey-Bass.

Tams, S., \& Arthur, M. (2010). New directions for boundaryless careers: Agency and interdepence in a changing world. Journal of Organizational Behavior, 31, 629-646. doi:10.1002/job.712

Templer, A. J., \& Cawsey, T. F. (1999). Rethinking career development in an era of portfolio careers. Career Development International, 2(2), 70-76. doi:10.1108/13620439910254669
Van Maanen, J. (1977). Organizational careers: Some new perspectives. New York: John Wiley \& Sons.

Veloso, E., \& Dutra, J. (2011). Carreiras sem fronteiras na gestão pessoal da transição profissional: Um estudo com ex-funcionários de uma instituição privatizada. Revista de Administração Contemporânea, 15(5), 834-854. doi:10.1590/ S1415-65552011000500004
Recebido: $15 / 08 / 2014$

$1^{a}$ revisão: $18 / 12 / 2014$

$2^{a}$ revisão: $13 / 03 / 2015$

Aceite final: 18/03/2015 